\title{
An Investigation of Neonatal Mortality and its Main Risk Factors in Hospitalized Late Preterm Infants
}

\author{
Behnaz Basiri \\ Hamadan University of Medical Sciences \\ zohre sadeghian ( $\square$ zohresadeghian96@gmail.com ) \\ Hamadan University of Medical Sciences \\ Nasrollah Pezeshki \\ Hamadan University of Medical Sciences \\ Mohammad Ali Seif Rabie \\ Hamadan University of Medical Sciences \\ Tara lakpour \\ Hamadan University of Medical Sciences
}

Research article

Keywords: Late preterm, Mortality, Risk factors, Outcome.

Posted Date: June 16th, 2021

DOI: https://doi.org/10.21203/rs.3.rs-602867/v1

License: (c) (1) This work is licensed under a Creative Commons Attribution 4.0 International License.

Read Full License 


\section{Abstract}

Background: Late preterm infants are born at a gestational age between $34^{+1}$ and $36^{+6}$ weeks, they have higher morbidity and mortality rates than term infants (gestational age $\geq 37$ weeks).

Methods: In this retrospective, cross-sectional study the medical records of late preterm infant hospitalized in Fatemieh hospital, Hamadan- Iran, were extracted during a one-year period (March 2018March 2019). Demographic information including sex, birth weight, causes of hospitalization and complications of the disease, length of stay, and outcome were assessed.

Results: Out of 150 infants studied in this research, $52 \%$ were female and $48 \%$ were male. Mean weight was $2775 \pm 572 \mathrm{gr}$ with mean admission days of $9.1 \pm 4.7$ days. Respiratory distress syndrome (RDS) was the most common cause of admission (80.7\%). Neonatal mortality rate was overall $7.3 \%$. According to logistic regression, need for resuscitation and ventilation, central nervous system (CNS) involvement (seizure) $(P \leq 0.001)$, congenital heart disease $(P \leq 0.001)$, need to surfactant administration $(P=0.034)$, pneumonia $(P=0.018)$, feeding problems $(P \leq 0.001)$, hypoglycemia $(P=0.048)$ and septicemia $(P \leq 0.001)$, could all possibly correlate with the occurrence of death in late-preterm infants.

Conclusion: Neonatal mortality is high in late preterm infants and can be predicted by the need to intensive supports for respiratory distress syndrome, CNS involvement, congenital heart disease, and septicemia.

\section{Background}

Infants born between the 34 to $36^{+6}$ weeks of gestation, also known as late-preterm infants, sometimes are similar to term infants (who are born between the weeks of 37 to 41) in terms of weight and size, but some cases need post-birth examinations by the medical staff (1). Late- preterm infants are physiologically and metabolically immature, that's why they are more vulnerable to neonatal and developmental complications than ordinary infants (2). Moreover, late-preterm infants are more likely to be readmitted to the hospital during the neonatal period, with an increasing trend in recent years (3). Several reasons have been reported for the increase in the number of late-preterm births, such as increased use of pregnancy technologies, increased care and medical interventions during pregnancy using fetal electronic monitoring and prenatal ultrasonography, and increased number of delivery and cesarean induction (4). Late-preterm infants have not been studied effectively and the biology and mechanism of the disease they experience are not fully known (5). Because of lung structure and its immature functional capacity, these infants are at higher risk for respiratory distress after birth and require oxygen and positive pressure ventilation and even admission to the neonatal intensive care unit (NICU) (6). The susceptibility to apnea in late-preterm infants is associated with different underlying factors such as the increased risk of hypoxic respiratory depression, decreased central chemical susceptibility to carbon dioxide, immaturity of pulmonary stimulatory receptors, increased respiratory depression, sensitivity to the larynx stimulation, and reduced strength of muscles dilating the upper 
airway (7). It is also assumed that late-preterm infants are at higher risk for central apnea because the central nervous system of these infants is immature (8). In addition, it is generally assumed in the cardiovascular system that immature structure and function restricts the rate of cardiovascular reserve available during stress (9). Preterm infants are at greater risk for hypoglycemia during postnatal development due to immature liver gluconeogenesis, immature lipolysis of the adipose tissue, hormonal imbalance, and failure of liver gluconeogenesis and ketogenesis (10). Feeding problems are common in late pre-terms. Results 54 infants had feeding difficulty. Jaundice and hyperbilirubinemia occur in latepreterm infants with higher frequency and longer duration compared to term infants because late-preterm infants have late maturation and deficiency of urethane 5'-diphosphate-glucuronyl-transferase (11). Due to deficiency of the immune system, late-preterm infants are at increased risk for a variety of infections which require antibiotic treatment (12).

This group of infants has recently been given more attention in neonatal science and the study of complications has led to the improvement of outcomes and reduction of infant mortality rate. Even latepreterm infants with no major clinical problems after birth might develop some alterations in the future, so we recommend that regular monitoring of late-preterm infants be carried out in the long term to prevent any developmental disorders from arising.

According to importance of this group of neonates (late pre-terms), and recent increasing rate of birth of them, we conducted this study to evaluating the main risk factors leading to death, so planning for improvement of survival can be achieved.

\section{Methods}

The present research was a retrospective cross-sectional study performed in Fatemieh hospital, Hamadan- Iran during March 2018-March 2019. The study population included 150 neonates born between the weeks 34 to 37 of gestation (inclusion criterion) admitted to the NICU and neonatal wards in Fatemieh hospital from March 2018 to March 2019. The only exclusion criterion was the incompleteness of the medical records. Information obtained from medical records was recorded in special checklists. The information included demographics (age and gender, gestational age), hyperbilirubinemia (bilirubin higher than 90th percentile for age), respiratory distress (at least on of following symptoms: tachypnea, grunting, nasal flaring, retraction) and apnea (lack of spontaneous breathing for 20 second or more), congenital heart diseases (CHD) (any abnormality in heart anatomy or function), length of hospitalization stay (days in hospital), and hypoglycemia (In the first 3 hours of life, the 4-24 hours and after 24 hours of life the blood glucose under $35 \mathrm{mg} / \mathrm{dl}$, under $40 \mathrm{mg} / \mathrm{dl}$ and under $45 \mathrm{mg} / \mathrm{dl}$, respectively represent hypoglycemia), sepsis (positive blood culture in addition to clinical presentation), feeding problems (vomiting, regurgitation, abdominal distention, poor sucking, poor swallowing). RDS was diagnosed if respiratory distress began after birth and characteristic ground glass appearance in chest X ray (CXR) was seen. Exogenous surfactant was administered if fraction of inspired oxygen (FiO2) $>30 \%$ was needed. 
All procedures were conducted under ethical instructions of the Ethical committee of Hamadan University of Medical Sciences, for the consideration and use of patient's laboratory data which encoded “IR.UMSHA.REC.1394.454”. Informed consent was obtained from all individual participants for whom identifying information is included in this article.

Collected data were analyzed using the SPSS software (Statistical Package for the Social Sciences, version 16.0, SPSS Inc, Chicago, Illinois, USA). Data were reported as below: qualitative variables by number and percentage, quantitative variables by mean and standard deviation, the correlation between variables by chi-square test, comparison of quantitative variables (mean) by the t-test and for detecting potential confounding factors for death in late-preterm infants simple logistic regression analysis were performed. Significance's level was considered as $p<0.05$.

\section{Results}

Out of 150 infants studied in this research, $52 \%$ were female and $48 \%$ were male. However, there was no significant difference between them $(p=0.467)$. The mean weight of infants was $2775 \pm 572 \mathrm{gr}$ and their mean hospitalization duration was $9.1 \pm 4.7$ days. $39 \%$ of infants were born by cesarean section (C/S) and $61 \%$ by vaginal delivery. All the pre-term infants received betamethasone. There was no significant difference between sexes in terms of weight and hospitalization time $(p=0.348, p=0.436$ respectively). The most common cause of hospitalization was respiratory distress (80.7\%). Other causes of hospitalization in NICU are shown in Table 1. 
Table 1

Baseline Characteristics in Survived and expired late-preterm infants

\begin{tabular}{|c|c|c|c|c|}
\hline Parameters & Survive(n = 139) & Expire $(n=11)$ & Total $(n=150)$ & P-value \\
\hline Sex & & & & 0.467 \\
\hline Male* & $64(90.1)$ & $7(9.9)$ & 71 & \\
\hline Female* & $75(94.9)$ & $4(5.1)$ & 79 & \\
\hline 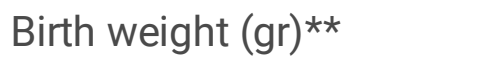 & $2781 \pm 580$ & $2700 \pm 483$ & $2775 \pm 572$ & 0.348 \\
\hline Length of stay (day) $)^{\star \star}$ & $8.6 \pm 4.3$ & $15.4 \pm 5.1$ & $9.1 \pm 4.7$ & 0.436 \\
\hline NICU admission, causes* & & & & 0.000 \\
\hline RDS & 119(98.3) & $2(1.7)$ & 121 & 0.000 \\
\hline CNS involvement (seizure) & $7(58.3)$ & $5(41.7)$ & 12 & 0.000 \\
\hline $\mathrm{CHD}$ & 13(76.5) & $4(23.5)$ & 17 & 0.000 \\
\hline Need to Ventilator* & & & & 0.000 \\
\hline Yes & $37(77.1)$ & $11(22.9)$ & 48 & \\
\hline No & $102(100)$ & $0(0)$ & 102 & \\
\hline Need to Surfactant* & & & & 0.034 \\
\hline Yes & $33(84.6)$ & $6(15.4)$ & 39 & \\
\hline No & $106(95.5)$ & $5(4.5)$ & 111 & \\
\hline Pneumonia* & & & & 0.018 \\
\hline Yes & $3(60)$ & $2(40)$ & 5 & \\
\hline No & 136(93.8) & $9(6.2)$ & 145 & \\
\hline Feeding problems* & & & & 0.000 \\
\hline Yes & $28(75.7)$ & $9(24.3)$ & 37 & \\
\hline No & $111(98.2)$ & $2(1.8)$ & 113 & \\
\hline Hypoglycemia* & & & & 0.048 \\
\hline \multicolumn{5}{|c|}{ 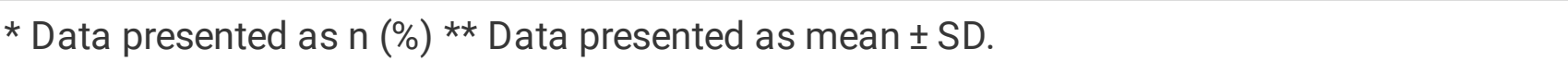 } \\
\hline \multicolumn{5}{|c|}{ NICU: Neonatal Intensive Care Unit } \\
\hline \multicolumn{5}{|c|}{ RDS: Respiratory Distress Syndrome } \\
\hline \multicolumn{5}{|l|}{ CNS: Central Nervous System } \\
\hline CHD: Congenital Heart Dis & & & & \\
\hline
\end{tabular}




\begin{tabular}{|c|c|c|c|c|}
\hline Parameters & Survive $(n=139)$ & Expire $(n=11)$ & Total $(n=150)$ & P-value \\
\hline Yes & 11(78.6) & $3(21.4)$ & 14 & \\
\hline No & 128(94.1) & $8(5.9)$ & 136 & \\
\hline Septicemia* & & & & 0.000 \\
\hline Yes & $5(55.6)$ & $4(44.4)$ & 9 & \\
\hline No & 133(95) & $7(5)$ & 140 & \\
\hline Need to Resuscitation* & & & & 0.000 \\
\hline Yes & $14(56)$ & $11(44)$ & 25 & \\
\hline No & $125(100)$ & $0(0)$ & 125 & \\
\hline Birth weight* & & & & 0.069 \\
\hline Low birth weight & $42(91.3)$ & $4(8.7)$ & 44 & \\
\hline Normal weight & 97(93.3) & $7(6.7)$ & 104 & \\
\hline \multicolumn{5}{|c|}{ * Data presented as $n(\%)$ ** Data presented as mean \pm SD. } \\
\hline \multicolumn{5}{|c|}{ NICU: Neonatal Intensive Care Unit } \\
\hline \multicolumn{5}{|c|}{ RDS: Respiratory Distress Syndrome } \\
\hline \multicolumn{5}{|c|}{ CNS: Central Nervous System } \\
\hline CHD: Congenital Heart D & & & & \\
\hline
\end{tabular}

According to logistic regression, need for resuscitation and ventilation, CNS involvement (seizure), congenital heart disease, need to surfactant administration, pneumonia, feeding problems, hypoglycemia and septicemia, could all strongly predict occurrence of death in late-preterm infants (Table 2). 
Table 2

Odds Ratio for Neonatal Mortality According to the Risk Factors

\begin{tabular}{|llllll|}
\hline Parameters & B & S.E & OR & $95 \% \mathrm{Cl}$ & P-Value \\
\hline Male sex & 0.718 & 0.649 & 2.051 & $0.574-7.324$ & 0.269 \\
\hline CNS involvement (seizure) & 3.75 & 0.923 & 42.5 & $6.967-259.262$ & 0.000 \\
\hline Congenital heart disease & 2.907 & 0.914 & 18.308 & $3.053-109.799$ & 0.000 \\
\hline Need to Ventilator use & - & - & - & - & - \\
\hline Need to surfactant & 1.349 & 0.637 & 3.855 & $1.105-13.447$ & $\mathbf{0 . 0 3 4}$ \\
\hline Pneumonia & 2.31 & 0.976 & 10.074 & $1.489-68.177$ & $\mathbf{0 . 0 1 8}$ \\
\hline Feeding problems & 2.881 & 0.81 & 17.839 & $3.648-87.329$ & $\mathbf{0 . 0 0 0}$ \\
\hline Hypoglycemia & 1.473 & 0.746 & 4.364 & $1.011-18.843$ & $\mathbf{0 . 0 4 8}$ \\
\hline Septicemia & 2.721 & 0.775 & 15.2 & $3.329-69.405$ & $\mathbf{0 . 0 0 0}$ \\
\hline Need to Resuscitation & - & - & - & - & - \\
\hline Low Birth Weight & 0.277 & 0.653 & 1.32 & $0.367-4.75$ & 0.671 \\
\hline Statistical analysis: Chi-square test \& T-independent Test. & & \\
\hline
\end{tabular}

Mortality in admitted term neonates, were very lower than late-preterms $(<1 \%)$ and the main causes of admission in this group were: Hypoxic-Ischemic-Encephalopathy, congenital anomalies, sepsis.

\section{Discussion}

This study has demonstrated that late-preterm infants suffer significant morbidity and mortality and hence, this population needs to increase observation and close monitoring during birth hospitalization. In our study, the major risks associated with the mortality of late-preterm neonates were need for resuscitation and mechanical ventilation, CNS involvement (seizure), congenital heart disease, surfactant administration, pneumonia, feeding problems, hypoglycemia and septicemia. The mean weight of infants in this study was $2804 \mathrm{gr}$. In a study conducted by Kitsommart (13), the mean weight of infants was reported to be $2576 \mathrm{gr}$, which is inconsistent with the present study. This difference can be attributed to ethnic differences between infants. Lotfalizadeh and colleagues (14) also reported that the mean birth weight of infants was 2743 grams, that is consistent with the present study.

About days of hospitalization, the results showed the minimum and maximum hospitalization days were 1 and 30 , respectively, with a mean of $9.1 \pm 4.7$ days. The mean hospitalization days in a study conducted by Kitsommart (13) was equal to 8.2. These results are consistent with the findings of the present study. The overall duration of hospitalization amongst late-preterm infants was twice than term infants in the 
study by Savitha (15). These results show that late-preterm infants have a higher risk of mortality, and therefore the pediatric physician must monitor late-preterm infants immediately after birth.

In terms of the cause of hospitalization, the results showed that the most common cause of hospitalization was respiratory distress syndrome (RDS) and transient tachypnea of the newborn (TTN) (80.7\%) and then cardiovascular diseases (11.3\%). In addition, the least cause was a CNS involvement (seizure) (8\%). Kitsommart (13) reported that the most common cause of hospitalization of late-preterm infants was related to the respiratory system, including respiratory distress (34\%), respiratory distress syndrome (RDS) $(11 \%)$, and TTN (14\%). This is consistent with the findings of the present study. In a study carried out by Correia and co-workers on respiratory morbidity in late-preterm neonates, $8.8 \%$ had RDS or TTN (16).

Tsai et al. studied morbidities in late-preterm infants and reported that respiratory problems are the most common cause of morbidities, which is consistent with the results of the present study (17). Differences between this study with ours is due to we studied only hospitalized late-preterms but they evaluated all late-preterms who were born in their center.

Since late-preterm infants may lack a complete respiratory system, natural evolution, and the ability to adapt to the environment, they require mechanical ventilation. The results of this study showed that $32 \%$ of infants needed mechanical ventilation. In studies of Kitsommart (13) and Tsai (17), 25.3\% and 26\% of infants needed mechanical ventilation, respectively. The results show that the need for mechanical ventilation is higher in this study which requires more attention and care in managing these infants.

Hyperbilirubinemia tends to be more intense and longer in late-preterm infants (18). Because of immaturity and delay in the bilirubin liver conjugation, late-preterm infants are twice more vulnerable to unconjugated pathologic hyperbilirubinemia than term infants $(13,19)$. The results of this study indicated that $42 \%$ of infants had hyperbilirubinemia. This is consistent with the findings of Tsai et al. (17) and Haroon et al. (20) who reported that the rate of hyperbilirubinemia was equal to $33 \%$ and $37.9 \%$, respectively. Scheuchenegger et al. also showed that the rate of hyperbilirubinemia was $29 \%$ (21).

The risk of hypoglycemia in late-preterm infants is three times higher than term infants. Hypoglycemia may occur at any age due to inappropriate and inadequate metabolic response to the discontinuation of glucose from the mother's blood (22). The results of this study showed that hypoglycemia is statistically significant )9\%) in late-preterm infants. Hosagasi and colleagues demonstrated the highest risk for hypoglycemia in the early postnatal period was present especially in late-preterm infants group (23). Tsai et al. reported that the prevalence of hypoglycemia is equal to $7 \%, 3.3 \%$, and $3 \%$ in infants aged 34 weeks, 35 weeks, and 36 weeks (17). Kitsommart et al. also showed that the prevalence of hypoglycemia among infants is equal to $32.5 \%$ (13). According to a study by Bulut in Turkey on short-term complications of late-preterm infants, they founded hypoglycemia and sepsis were significantly higher in these infants compared to term infants (24). 
Late-preterm infants have a 3.2 times higher risk of sepsis compared to term infants (25). Due to the lack of evolution of the immune system, late-preterm infants are at increased risk of a variety of infections and need antibiotics. In the present study, $98 \%$ of infants had received antibiotics. According to our results, Drazdienè and co-workers demonstrated "during one respiratory syncytial virus (RSV) season, the incidence of lower respiratory tract infection (LRTI) hospitalizations among late-preterm infants were $6.5 \%$ and the incidence of RSV LRTI hospitalizations was $1.7 \%$. The majority of hospitalized infants $(94.7 \%)$ had a mild or moderate respiratory illness (26). Similarly, the frequency of need for antibiotics was reported to be $83.5 \%$ in the study conducted by Lotfalizadeh and colleagues (14). However, Kitsommart et al. reported that the need for antibiotics among infants was equal to $56.5 \%$ which is less than the present study (13). In addition, the prevalence of sepsis )including pneumonia) in this study was $9.4 \%$. This figure was reported to be $13.6 \%$ by Savitha et al. (15), and $10.3 \%$ by Sahana et al. (27) which are consistent with the present study. Jakiel et al. also showed that the prevalence of sepsis is equal to $3.3 \%$. He also found that the prevalence of sepsis in term infants is significantly lower than late-preterm infants (28). In another study which performed by Swiss researcher to evaluate the risk of bacterial infections in late-preterm neonates, Stocker and colleagues suggested that asymptomatic infants in the first 48 hours after birth should be closely monitored, also symptomatic infants immediately need an intravenous antibiotics administration (29). Considering the higher prevalence of sepsis in this study than other studies, there is a need for paying more attention to care and preventing the transmission of infectious agents through examination with contaminated hands and other means of transmission.

The results of this study showed that the risk of congenital heart diseases (CHD) is statistically significant in late-preterm infants. congenital anomalies were the direct cause of neonatal deaths in the study by Abdel Razeq et al (30).

The need for surfactant in the present study was $26 \%$ and this amount of surfactant requirement in latepreterm infants is statistically significant. This figure in the study of Kitsommart et al. was reported to be $6.5 \%$, which is not consistent with the present study (13). The incidence of respiratory problems such as RDS, TTN, and ventilator requirements in late-preterm neonates is higher than terms (31). In line with our results, Olivier and colleagues showed that minimally invasive surfactant therapy for respiratory distress syndrome management in moderate and late-preterm infants was associated with a significant reduction of mechanical ventilation exposure and pneumothorax occurrence (32).

The late-preterm infants had higher rates of resuscitation in the delivery room such as chest compression and intubation than control group. In the studies by de Araújo et al. (18) and Afjeh et al. (33) there were a positive correlation between the need for resuscitation and preterm birth which are inconsistent with the present study. In the present study, $16.8 \%$ of infants needed resuscitation measures and there was a difference between sexes, as male infants needed these measures more than females. The need for resuscitation measures was reported to be $21 \%$ and $18 \%$ by Haroon et al. (20) and Kitsommart et al. (13), which are consistent with the findings of the present study. 
In our study late-preterm infants had more feeding problems that required nutritional and supportive management. Similar results were found by Savitha et al. (15) and Wagh et al. (34). The best way to feed late-preterm infants is breastfeeding because it is to the benefit of both the mother and the infant. However, these infants need more care and support than term ones, because the sucking- swallowing coordination and ingestion is still immature in these infants and they have nutritional problems. In the present study, the feeding problem is statistically significant in late-preterm infants. Johnson and coworkers demonstrated Infants born late and moderately preterm; 32-36 weeks of gestation, are at increased risk of oral motor and picky eating problems at 2-year corrected age. However, these are mediated by other neurobehavioral sequelae in this population (35). The results of this study showed that $24.7 \%$ of infants had feeding problem. This is consistent with the findings of Lotfalizadeh et al. (14) where the prevalence of nutritional problems among infants was equal to $20 \%$.

Late-preterm infants also are at greater risk of developing neurological problems than terms. Jia You and co-workers were observed that the late-preterm infants had impairments in social competence and social cognition before 3 years of age (36). Given the increased risk of death caused by the seizure and longterm complications of this condition, it is necessary to pay more attention to the risk factors of seizure at this age, such as hypoglycemia, hypothermia, and infections.

The rate of mortality in late-preterm infants is three times higher than other infants. In the US, $10 \%$ of all neonatal deaths are related to late-preterm infants (37). In the present study, the mortality rate of admitted late-preterm infants was equal to $7.3 \%$. This figure in studies conducted by Kitsommart et al. (13) and Tsai et al. (17) were $0.7 \%$ and $3 \%$ respectively. The high mortality rate in our study may be due to the fact that our hospital is a tertiary care referral center and hence, we admit sicker late-preterm infants that they had serious morbidities like need to resuscitation at delivery room, respiratory distress and sepsis.

\section{Conclusion}

The results of this study showed that mortality is high in late-preterm infants and can be predicted by the need to intensive supports for respiratory distress syndrome, CNS involvement, congenital heart disease, and Septicemia. Therefore, identifying and management of these predictive factors can reduce neonatal mortality in these infants.

\section{Abbreviations}

RDS

respiratory distress syndrome

CNS

central nervous system

$\mathrm{NICU}$

neonatal intensive care unit 
CHD

congenital heart diseases

CXR

chest $X$ ray

$\mathrm{FiO} 2$

fraction of inspired oxygen

$\mathrm{C} / \mathrm{S}$

cesarean section

TTN

transient tachypnea of the newborn

RSV

respiratory syncytial virus

LRTI

lower respiratory tract infection

\section{Declarations}

Ethics approval and consent to participate: All procedures performed in this study involving human participants were in accordance with the ethical standards and approved by the Hamadan University of Medical Since ethical Committee and the 1964 Helsinki Declaration and its later amendments or comparable ethical standards.

Consent for publication: All authors give their consent to submission of this article to Maternal Health, Neonatology and Perinatology.

Availability of data and material: The authors confirm that the data supporting the findings of this study are available within the article

Competing interests: All authors certify that they have no affiliations with or involvement in any organization or entity with any financial interest (such as honoraria; educational grants; participation in speakers' bureaus; membership, employment, consultancies, stock ownership, or other equity interest; and expert testimony or patent-licensing arrangements), or non-financial interest (such as personal or professional relationships, affiliations, knowledge or beliefs) in the subject matter or materials discussed in this manuscript.

Funding: None

Authors' contributions: Zohre Sadeghian and Behnaz Basiri have given substantial contributions to the conception or the design of the manuscript, Nasrollah Pezeshki, Mohammad Ali Seif Rabie to acquisition, analysis and interpretation of the data. All authors have participated to drafting the manuscript, Mohammad Ali Seif Rabie, Tara lakpour, revised it critically. Zohre Sadeghian supervised this project. All 
authors read and approved the final version of the manuscript. All authors contributed equally to the manuscript and read and approved the final version of the manuscript.

Acknowledgements: Not applicable

\section{References}

1. Isayama T, Lewis-Mikhael AM, O'Reilly D, Beyene J, McDonald SD. Health Services Use by Late Preterm and Term Infants From Infancy to Adulthood: A Meta-analysis. Pediatrics. 2017;140(1).

2. Morgan JC, Boyle EM. The late preterm infant. Paediatrics Child Health. 2018;28(1):13-7.

3. Shin JS, Kim YB, Lee YH, Shim GH, Chey MJ. Comparisons of clinical characteristics affecting readmission between late preterm infants and moderate preterm infants or full-term infants. Neonatal Med. 2016;23(4):211.

4. Bassil KL, Yasseen AS III, Walker M, Sgro MD, Shah PS, Smith GN, et al. The association between obstetrical interventions and late preterm birth. American journal of obstetrics gynecology. 2014;210(6):538. e1-. e9.

5. Júnior LCM, Júnior RP, Rosa IRM. Late prematurity: a systematic review. Jornal de pediatria. 2014;90(3):221-31.

6. Lakshminrusimha S, Konduri G, Steinhorn RH. Considerations in the management of hypoxemic respiratory failure and persistent pulmonary hypertension in term and late preterm neonates. $\mathrm{J}$ Perinatol. 2016;36(s2):12.

7. Kinney HC. editor The near-term (late preterm) human brain and risk for periventricular leukomalacia: a review. Seminars in perinatology. Elsevier; 2006.

8. Laptook AR. Neurologic and metabolic issues in moderately preterm, late preterm, and early term infants. Clinics in perinatology. 2013;40(4):723-38.

9. Lingwood BE, Eiby YA, Bjorkman ST, Miller SM, Wright IM. Supporting preterm cardiovascular function. Clin Exp Pharmacol Physiol. 2019;46(3):274-9.

10. Kugelman A, Colin AA. Late preterm infants: near term but still in a critical developmental time period. Pediatrics. 2013;132(4):741-51.

11. Miller M, Fanaroff A, Martin R. Respiratory disorders in preterm and term infants. Fanaroff and Martin's Neonatal-Perinatal Medicine, Diseases of the Fetus and Infant. 2002:1122-46.

12. Van Herk W, El Helou S, Janota J, Hagmann C, Klingenberg C, Staub E, et al. Variation in current management of term and late-preterm neonates at risk for early-onset sepsis: an international survey and review of guidelines. Pediatr Infect Dis J. 2016;35(5):494-500.

13. Kitsommart R, Janes M, Mahajan V, Rahman A, Seidlitz W, Wilson J, et al. Outcomes of late-preterm infants: a retrospective, single-center, Canadian study. Clin Pediatr. 2009;48(8):844-50.

14. Lotfalizadeh M, Ghomian N, Reyhani A. The effects of progesterone therapy on the gestation length and reduction of neonatal complications in patients who had received tocolytic therapy for acute 
phase of preterm labor. Iranian Red Crescent Medical Journal. 2013;15(10).

15. MR S, Sanjee SS. Morbidity and mortality profile of late preterm neonates as compared to term neonates from a tertiary care centre in Mysore, India. International Journal of Contemporary Pediatrics. 2016;3(1):164.

16. Correia C, Rocha G, Flor-DE-Lima F, Guimarães H. Respiratory morbidity in late preterm infants. Minerva pediatrica. 2016.

17. Tsai M-L, Lien R, Chiang M-C, Hsu J-F, Fu R-H, Chu S-M, et al. Prevalence and morbidity of late preterm infants: current status in a medical center of Northern Taiwan. Pediatrics Neonatology. 2012;53(3):171-7.

18. Araújo BFd, Zatti H, Madi JM, Coelho MB, Olmi FB, Canabarro CT. Analysis of neonatal morbidity and mortality in late-preterm newborn infants. Jornal de pediatria. 2012;88(3):259-66.

19. Amin SB, Wang H, Laroia N, Orlando M. Unbound bilirubin and auditory neuropathy spectrum disorder in late preterm and term infants with severe jaundice. J Pediatr. 2016;173:84-9.

20. Haroon A, Ali SR, Ahmed S, Maheen H. Short-term neonatal outcome in late preterm vs. term infants. JCPSP: Journal of the College of Physicians Surgeons Pakistan. 2014;24(1):34.

21. Scheuchenegger A, Lechner E, Wiesinger-Eidenberger G, Weissensteiner M, Wagner O, Schimetta W, et al. Short-term morbidities in moderate and late preterm infants. Klinische Pädiatrie. 2014;226(04):216-20.

22. Clapp DW. editor Developmental regulation of the immune system. Seminars in perinatology. Elsevier; 2006.

23. Hosagasi NH, Aydin M, Zenciroglu A, Ustun N, Beken S. Incidence of hypoglycemia in newborns at risk and an audit of the 2011 American academy of pediatrics guideline for hypoglycemia. Pediatr Neonatol. 2018;59(4):368-74.

24. Bulut C, Gürsoy T, Ovalı F. Short-term outcomes and mortality of late preterm infants. Balkan medical journal. 2016;33(2):198.

25. Jaiswal A, Murki S, Gaddam P, Reddy A. Early neonatal morbidities in late preterm infants. Indian pediatrics. 2011;48(8):607.

26. Drazdiene N, Tameliene R, Kviluna D, Saik P, Saik E, Zaikauskiene J. Hospitalisation of late preterm infants due to lower respiratory tract infections in Lithuania, Latvia, and Estonia: incidence, disease severity, and risk factors. Acta medica Lituanica. 2018;25(2):76-85.

27. Sahana AE, Sunil R. Sreekrishna. Short-term outcome of late preterms. Int J Med Appl Sci. 2014;3:205-11.

28. Jakiel G, Wilinska M, Binskowska M, Kowal A, Rumowska S, Ciebiera M. Late preterm infants-impact of perinatal factors on neonatal results. A clinical study. Annals of Agricultural and Environmental Medicine. 2015;22(3).

29. Stocker M, Berger C, McDougall J, Giannoni E. Recommendations for term and late preterm infants at risk for perinatal bacterial infection. Swiss Med Wkly. 2013;143:w13873. 
30. Razeq NMA, Khader YS, Batieha AM. The incidence, risk factors, and mortality of preterm neonates: A prospective study from Jordan (2012-2013). Turkish journal of obstetrics gynecology. 2017;14(1):28.

31. Liu S, Tong $X$. The clinical comparative study of preterm respiratory distress syndrome and transient tachypnea of newborn. Zhonghua er ke za zhi = Chinese. journal of pediatrics. 2015;53(2):104-8.

32. Olivier F, Nadeau S, Belanger S, Julien AS, Masse E, Ali N, et al. Efficacy of minimally invasive surfactant therapy in moderate and late preterm infants: A multicentre randomized control trial. Paediatr Child Health. 2017;22(3):120-4.

33. Afjeh S-A, Sabzehei M-K, Esmaili F. Neonatal resuscitation in the delivery room from a tertiary level hospital: risk factors and outcome. Iranian journal of pediatrics. 2013;23(6):675.

34. Wagh AS, Tewari VV, Naveen Jain D. Comparison of neonatal morbidities of late preterm with term born babies. Sepsis (CRP > 10 mg/L). 2012;114:10.4.

35. Johnson S, Matthews R, Draper ES, Field DJ, Manktelow BN, Marlow N, et al. Eating difficulties in children born late and moderately preterm at $2 \mathrm{y}$ of age: a prospective population-based cohort study. Am J Clin Nutr. 2016;103(2):406-14.

36. You J, Yang HJ, Hao MC, Zheng JJ. Late Preterm Infants' Social Competence, Motor Development, and Cognition. Frontiers in psychiatry. 2019;10:69.

37. Engle WA. editor A recommendation for the definition of "late preterm"(near-term) and the birth weight-gestational age classification system. Seminars in perinatology. Elsevier; 2006. 